\title{
Darwinian fisheries science needs to consider realistic fishing pressures over evolutionary time scales
}

\author{
Christopher J. Brown ${ }^{1,5, *}$, Alistair J. Hobday ${ }^{1,2}$, Philippe E. Ziegler ${ }^{3}$, \\ Dirk C. Welsford ${ }^{4}$ \\ ${ }^{1}$ School of Zoology, University of Tasmania, Hobart 7000, Australia \\ ${ }^{2}$ CSIRO Marine and Atmospheric Research, Castray Esplanade, Hobart, Tasmania 7001, Australia \\ ${ }^{3}$ Tasmanian Aquaculture and Fisheries Institute, University of Tasmania, Hobart, Tasmania 7000, Australia \\ ${ }^{4}$ Australian Antarctic Division, Department of Environment, Water, Heritage and the Arts, Kingston, Tasmania 7050, \\ Australia \\ ${ }^{5}$ Present address: School of Integrative Biology, University of Queensland, Brisbane 4072, Australia
}

\begin{abstract}
The apparently intense selective differentials imposed by many fisheries may drive the rapid evolution of growth rates. In a widely-cited laboratory experiment, Conover \& Munch (2002; Science 297:94-96) found considerable evolutionary change in the size of harvested fish over 4 generations. Their empirical model has since been used to estimate the impact of fishery-driven evolution on fishery sustainability. Using a mathematical, individual-based model (IBM) that simulates that experiment, we showed that the selection imposed in the Conover \& Munch (2002) model is unrealistically strong when compared to harvest rates in wild fisheries. We inferred the evolutionary change that could be expected over the timescale used by Conover \& Munch (2002), had they simulated more realistic harvest regimes, and found that the magnitude in their original experiment was 2.5 to 5 times greater. However, over evolutionary timescales of 30 generations and with realistic fishing pressure, the results of Conover \& Munch (2002) are comparable to wild fisheries. This simulation result provides support for the use of empirical models to predict the impacts of fishery-driven evolution on yields and sustainability. Future models should consider the timing of fishing events, the trade-off between size, maturation and growth, and density-dependent effects for a comprehensive analysis of the consequences of fishery-driven evolution.
\end{abstract}

KEY WORDS: Fishery-driven evolution · Evolution · Fisheries $\cdot$ Heritability $\cdot$ Life history $\cdot$ Selection Individual-based model

Resale or republication not permitted without written consent of the publisher

\section{INTRODUCTION}

Strong fishing selection pressure, in combination with moderate levels of heritable genetic variation, have been shown to drive the Darwinian evolution of life history traits such as growth rate and size-at-maturity in numerous fished populations (Jørgensen et al. 2007). The magnitude of change in these life-history traits is so great that it will most likely result in lower sustainable yields (Law 2000) and may even have contributed to stock collapse in some fisheries (Olsen et al. 2004). Hence, the Darwinian fishery paradigm can no longer be ignored if fish stocks are to be managed for sustainability or recovery from over-exploitation (Conover 2000).

When predicting the magnitude of evolutionary change, it is important to consider what proportion of the variance in the life-history trait can be attributed 
to genetic variation, the selective strength of fishing, and appropriate timescales. The genetically controlled proportion of life history traits is probably moderate, estimated at 0.2 to 0.3 for fish (Law 2000, Stokes \& Law 2000). The selective pressure exerted by different fisheries is variable and depends upon the harvest rate and the degree to which the fishery targets particular components of the population. Gillnets can be highly size selective (Sinclair et al. 2002), and focussing fishing effort on particular fish life history stages, such as the spawning aggregations, can also exert strong selective pressures for delayed maturity (Law \& Grey 1989). Given these factors, fishery-driven evolution is highly likely in fish stocks that have been fished for tens to hundreds of generations. A review of empirical studies of fishery-driven evolution suggests that, in heavily fished populations, a $25 \%$ evolutionary change in life-history traits over 30 to 40 generations is possible (Jørgensen et al. 2007).

The gradual nature of evolutionary trends, as well as confounding environmental factors such as densitydependent growth compensation, impede the detection of life-history evolution in wild fisheries. A number of studies, using a variety of methods, have tried to separate environmental from genetic effects in wild fisheries (e.g. Rijnsdorp 1993, Heino et al. 2002, Swain et al. 2007). However, the statistical techniques used to identify potential evolutionary trends necessarily make important simplifying assumptions (Dieckmann \& Heino 2007, Wright 2007). Thus, it is necessary to consider a wide variety of sources of evidence and study techniques. Predictions of fishery-driven evolution in wild fisheries are complemented by models, because they enable the simulation of processes driving evolutionary change in life history traits without other confounding forces. Both mathematical and empirical models have been used to explore the impacts of fishery-driven evolution on life-history traits and fishery sustainability (Conover \& Munch 2002, Reznick \& Ghalambor 2005, Williams \& Shertzer 2005, de Roos et al. 2006, Andersen et al. 2007).

The empirical study by Conover \& Munch (2002) has received a particularly great amount of attention (148 citations on ISI Web of Knowledge, March 2008, http://wok.mimas.ac.uk). This could largely be attributed to the evidence for rapid evolutionary change, resulting in a reduction of $25 \%$ in size at age over 4 generations, presented in the study. Such drastic changes in size would have severe implications for yields in wild fisheries and would reduce sustainability through the evolution of genetically correlated lifehistory traits such as fecundity (Conover \& Munch 2002, Conover et al. 2005, Munch et al. 2005, Walsh et al. 2006). However, Conover \& Munch (2002) have been criticised for using extreme harvest rates and artificially constraining age at maturity, conditions that may produce unrealistically great evolutionary change over short timescales (Hilborn 2006, Conover \& Munch 2007, Hilborn 2007). Thus, they may overestimate the impact of fishery-driven evolution on sustainability and yields in wild fisheries.

To determine the relevance of their studies to wild fisheries, we developed a mathematical, individualbased model (IBM) that simulated the Conover \& Munch (2002) experiment and considered the evolutionary change in growth under different harvesting regimes and over more realistic evolutionary timescales. This enabled us to compare the results of Conover \& Munch (2002) with those that might have been expected had their experiment used fishery pressures and evolutionary timescales that occur in wild fisheries.

\section{METHODS}

Model structure. Our IBM simulated growth, fishing, spawning and inheritance cycles from Conover \& Munch (2002). Similar to their empirical model, replicate populations of 1000 larval fish of the same age 'grew' for $190 \mathrm{~d}$ in our simulation. On the 190th day, each population was 'harvested' according to one of 3 rules: fishing removed either the (1) largest (large-harvested), (2) smallest (small-harvested), or (3) a random (random-harvested) $90 \%$ of individuals. Conover \& Munch (2002) artificially induced the surviving 100 individuals to spawn, and their offspring were taken to breed the next generation of 1000 fish. This fishery pattern was repeated for 4 generations. In our IBM, in contrast, surviving individuals 'spawned' and contributed equal numbers of model offspring to the next generation of 1000 individuals. This cycle was repeated for up to 100 generations (Fig. 1).

Individual growth and size. Each individual in the IBM simulations grew on a daily time-step. Growth was simulated using a function relating size (length in $\mathrm{mm}$ ) and age (in d), following the description of growth of Atlantic silverside Menidia menidia in Munch et al. (2005):

$$
S_{a}=D a^{2}+\theta a+G
$$

where $S_{a}$ is the size at age $a_{i} D$ is the age-squared growth coefficient; $\theta$ is the growth coefficient and $G$ is the size-at-birth for an individual.

Variable size at age (upon which harvesting selection acts) was simulated by assigning individual growth coefficients. Individuals with greater growth coefficients grew faster. The age-squared coefficient was kept constant, because small changes in its value effect much greater changes than the growth coefficient in the 
growth curve. Assumptions about static or evolving size at birth were tested in sensitivity analyses.

In the first generation, growth coefficient values were randomly selected from a normal distribution (for parameter values see Table 1). The distribution was generated using the mean and standard deviation of size-at$190 \mathrm{~d}$ in the first generation of random-harvested trials from the Conover \& Munch (2002) experiment. In following generations, the growth constant was inherited from individuals that spawned. All individuals that survived fishing spawned, and all spawning individuals contributed equal numbers of offspring to the next generation. Individual length was converted to harvested yield in weight, making IBM results directly comparable with those reported by Conover \& Munch (2002). This equation followed the form typical for length-weight relationships:

$$
W=\alpha L^{\beta}
$$

where $\alpha$ and $\beta$ are constants.

Parameters for Eq. 2 (Table 1) were calculated using the mean weight of harvested fish in first generation random-harvested trials from Conover \& Munch (2002) and the mean size of unselectively harvested fish in Munch et al. (2005). The power parameter $\beta$, was set at a typical level for length-weight relationships (Blueweiss et al. 1978).

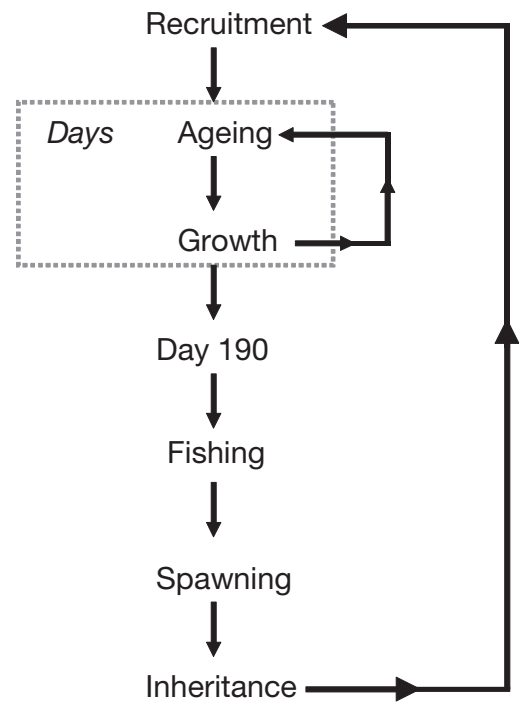

Fig. 1. Schematic of individual-based model components cycled each generation in the Atlantic silverside model. Components inside the dashed box were updated each model day
Inheritance of growth. Individual phenotypes are determined by a combination of environmental and genetic effects. The genetic component of the variance of a quantitative trait is composed of additive, dominant and epistatic components and interactions between these components (broad-sense heritability sensu Falconer \& Mackay 1996). The additive component is of greatest interest in selection experiments, since additive genes combine cumulatively to influence the phenotypical expression of a trait; hence, the evolutionary response is predictable under selection (Falconer \& Mackay 1996). The narrow-sense heritability (henceforth referred to as heritability, $h^{2}$ ) is the proportion of phenotypic variance observed in a quantitative trait that can be explained by additive genetic variation:

$$
h^{2}=V_{\mathrm{a}} / V_{\mathrm{p}}
$$

where $V_{\mathrm{a}}$ is the proportion of phenotypic variance that is explained by additive genetic variance and $V_{\mathrm{p}}$ is the total phenotypic variance in a population.

Conover \& Munch (2002) set the age at maturity by artificial induction of spawning in all individuals that survived harvesting; hence, it was only necessary to simulate heritability of size at age. In our IBM simulations, the growth coefficient representing size at age was inherited with a heritability of 0.2 , based on the estimates by Conover \& Munch (2002). Inheritance of the growth coefficient was simulated by using the 'breeders equation' to calculate the evolutionary response $R$ to the selection of a trait in a population:

$$
R_{\mathrm{T}}=h_{\mathrm{T}}^{2} \Delta S_{\mathrm{T}}
$$

where $\mathrm{T}$ is the trait, $h_{\mathrm{T}}^{2}$ is the heritability of the trait $\mathrm{T}$ and $\Delta S_{\mathrm{T}}$ is the difference in the mean number of parents displaying the phenotype for trait $\mathrm{T}$ before and after selection. 
The breeders equation has commonly been used in other models of fishery-driven evolution (Munch et al. 2005, de Roos et al. 2006, Andersen et al. 2007). In our model, it was used to calculate the phenotypic mean for a normal distribution of possible offspring trait values for each new generation, given the mean trait values for all parents after selection. The phenotypic standard deviation was estimated from Conover \& Munch (2002) and assumed to be constant in all our IBM simulations (Table 1). The trait values for growth of individuals in the new generation were then randomly selected from this distribution. In real animal populations, selection tends to erode additive genetic diversity, decreasing the phenotypic variability on which selection can act (Falconer \& Mackay 1996). The evolutionary rate in Conover \& Munch (2002) showed no sign of slowing over the timescales considered; hence, simulating genetic diversity as a constant is a valid assumption for our model, provided the evolutionary rate of change does not exceed that observed in Conover \& Munch (2002).

The evolution of adult size may also be expected to be correlated with the evolution of size at other ages. The growth equation (Eq. 1) includes a term for size at birth, so it is important to consider co-evolution of this trait. We considered the co-heritability of size at birth and size at age $190 \mathrm{~d}$. Co-heritability describes the expected change in a trait given selection of another trait. Thus, the evolutionary response $R$ of a genetically correlated trait can be calculated based on the selection of another trait:

$$
R_{\mathrm{P}}=h_{\mathrm{T}, \mathrm{P}}^{2} \Delta S_{\mathrm{T}}
$$

where $\mathrm{P}$ is the correlated trait, $h_{\mathrm{T}, \mathrm{P}}^{2}$ is the co-heritability of the traits $\mathrm{T}$ and $\mathrm{P}$, and $\Delta S_{\mathrm{T}}$ is the difference of the mean number of parents displaying the phenotype for trait $\mathrm{T}$ before and after selection (Falconer \& Mackay 1996).

The breeders equation for co-heritability was used to calculate the size at birth parameter $G$ for each individual specific growth coefficient. The effect of different coheritability values was explored in sensitivity analyses.

Heritability of the growth trait in our IBM was confirmed to represent heritability of the size at age $190 \mathrm{~d}$ by plotting the cumulative selective differential for different heritability values. The slope of this plot is an estimate of heritability of size at age (Falconer \& Mackay 1996). The estimates match the heritability values for the growth constant used in our simulations (Fig. 2). Furthermore, our simulations confirm that the model represented evolution linearly for the magnitude of change considered, which was a necessary assumption for a heritability equation that does not consider changes in genetic variance. When the cumulative selection differential is plotted against the mean

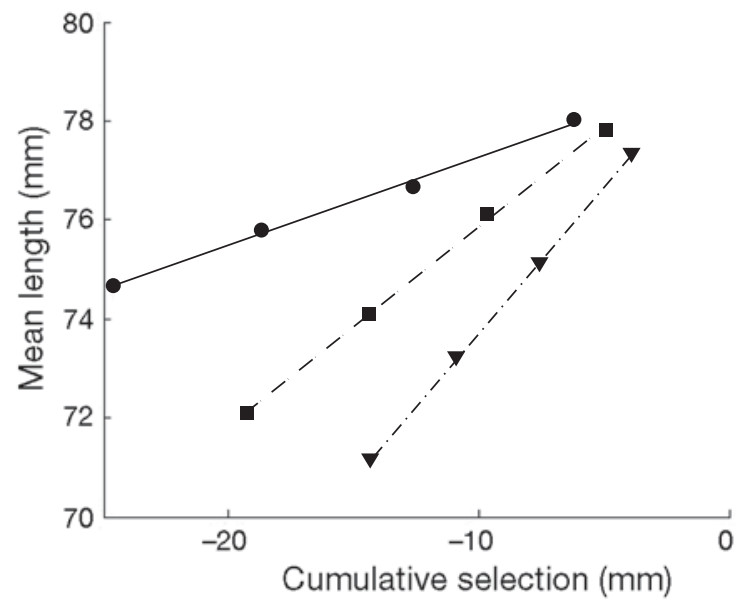

Fig. 2. Cumulative changes in the mean phenotype of parents caused by selection over 4 generations (cumulative selection) against the mean length of the population at different heritability values. Slopes of the lines give the heritability of size at age $190 \mathrm{~d}$ for each generation. If all of the variability in growth was genetically controlled $\left(h^{2}=1\right)$, the change in mean length would correspond exactly with changes in cumulative selection. The slopes of the fitted lines are 0.20

(一-), $0.40(----)$ and $0.60(-\cdot \nabla-\cdot)$ for trials with heritability of $0.2,0.4$ and 0.6 , respectively

length, our IBM shows less residual variance than the experimental results of Conover \& Munch (2002) (Fig. $2, R^{2}=0.99$ for all scenarios), due to the averaging approach taken in the breeders equation (Eq. 4).

Model simulations. Initially, a base-case simulation, using parameters from Conover \& Munch (2002), was compared with results from that study. Then, simulations were conducted to test sensitivity of our IBM to parameter assumptions about the variance in growth rates in a generation, the heritability of growth rates and the co-heritability of growth rates and size at birth. In order to contextualise the selective pressure indicated by the Conover \& Munch (2002) experiment, it was necessary to compare the results from their experiment with selective pressures from a wide range of wild fisheries. Because it is complicated and dataintensive to calculate selective pressure in wild fisheries (Sinclair et al. 2002), we used the maximum estimated yearly harvest rates (proportion of fishable stock removed per year) for different wild fisheries as an indicator of fishery pressure. Maximum yearly harvest rates in 82 wild fisheries were calculated from the maximum fishing mortality rate (instantaneous rate) from the literature and databases of fishery mortality rates (Appendix 1). We then simulated evolution in the Conover \& Munch (2002) experiment with our IBM, applying harvest rates of 0 to 1 to the vulnerable proportion of the population, which included 5 to $100 \%$ of the largest individuals. Thus, the evolutionary change expected in the original Conover \& Munch (2002) 
experiment could be compared with the evolutionary change expected when using more realistic harvest rates from wild fisheries. To calculate realistic evolutionary timescales, we considered the number of generations required to reproduce the result from Conover \& Munch (2002) across the range of fishery selective pressures.

\section{RESULTS}

\section{Comparison of our model with the Conover \& Munch (2002) experiment}

A comparison of the Conover \& Munch (2002) experiment (Fig. 3A) with our results (Fig. 3B) shows that the IBM approximates the general trends of increasing size in small-harvested trials and decreasing size in large-harvested trials observed in the empirical exper-

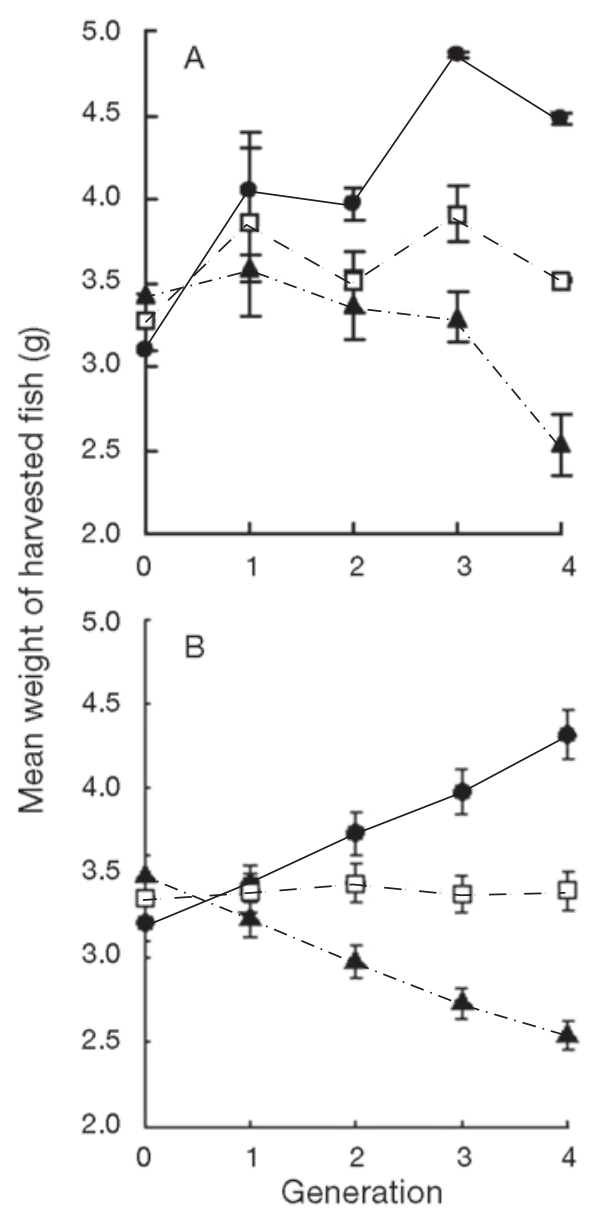

Fig. 3. Change in mean weight $( \pm \mathrm{SE})$ of harvested fish; (A) from Conover \& Munch (2002), reprinted with permission from AAAS, and (B) individual-based model (IBM) populations. Populations are either large-harvested (ム), smallharvested $(\bullet)$ or random-harvested $(\square)$ iment. Our simulated evolutionary trends are more consistent and slightly underestimated when compared with Conover \& Munch (2002). The extra variation in Conover \& Munch (2002) could be explained by random genetic sampling effects or non-genetic interannual variation, factors not accounted for in our simple additive genetic model. Underestimation of evolutionary change by our IBM could be due to underestimation of key IBM parameters, evolution of other life-history traits genetically correlated with size at age $190 \mathrm{~d}$, or non-additive genetic effects in the empirical experiment. Whilst evolutionary models of non-additive genetic effects are achievable (e.g. Hallander \& Waldmann 2007), not enough is known about non-additive genetic effects in silverside to include them in this simple model.

The minor underestimation of the evolutionary magnitude in Conover \& Munch (2002) may also be caused by the assumption of constant size at birth in all generations. Thus, we also considered the co-heritability of size at birth and size at age $190 \mathrm{~d}$ for co-heritability values ranging from 0 to 0.01 . Munch et al. (2005) published values for co-heritability of size at age $190 \mathrm{~d}$ and earlier ages for the model system used by Conover \& Munch (2002). The magnitude of the co-heritability decreased for younger ages (Munch et al. 2005). Thus, the upper limit for this sensitivity exploration (0.01) was chosen as twice the estimate of co-heritability of size at age $190 \mathrm{~d}$ and size at age $7 \mathrm{~d}$ published in Munch et al. (2005). After 4 generations, there is no difference between the mean weight of harvested fish for simulations with co-heritability values ranging from 0 and 0.01 . Simulations of longer time-scales produced similar results. Thus for simplicity, in subsequent simulations constant size at birth is assumed over all generations.

The sensitivity of evolutionary change to 2 other key parameters in our IBM was also tested. Sensitivity of evolutionary change to heritability $\left(h^{2}=0\right.$ to 1$)$ was conducted, whilst holding population variability constant at $\mathrm{CV}=0.7$. Sensitivity to population variability $(\mathrm{CV}=0.05$ to 1$)$ was also tested whilst holding the heritability constant at 0.2 . The IBM showed low sensitivity to both parameters. An increase in heritability of 0.1 resulted in a linear decrease of $8.3 \%(0.31 \mathrm{~g})$ in the mean weight of harvested fish after 4 generations, compared to the harvest size in the first generation. An increase in population variability of 0.1 resulted in a linear decrease of $2.3 \%(0.09 \mathrm{~g})$. Linear sensitivity to key parameters means that, if population variability or heritability were underestimated in the IBM, the relative magnitude of evolutionary change in the Conover \& Munch (2002) would not change for fishery scenarios with alternative selective pressures. Based on these results, our IBM was then used to compare evolutionary change under different fishery conditions. 

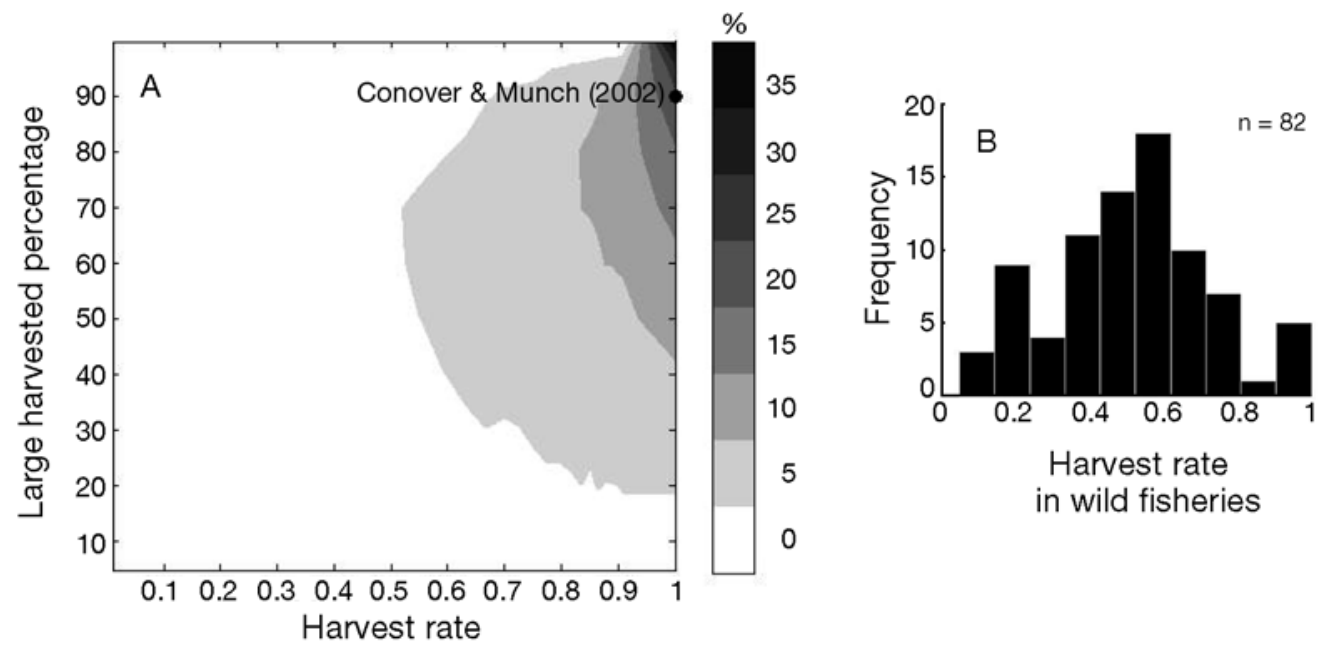

Fig. 4. (A) Contour plot of the change in mean weight (\%) of all fish after 4 generations of harvesting, using different fishery scenarios, in the individual-based (IBM) model. The dot indicates size selectivity and harvest rate in Conover \& Munch (2002) (B) Histogram of the maximum yearly harvest rate in 82 wild fisheries for comparison with the harvest rate used in Conover \& Munch (2002). For sources of fisheries data see Appendix 1

\section{Selection in the IBM compared to wild fisheries}

Individual-based model scenarios for evolutionary change under different fishery scenarios indicated strong effects of both the harvest rate and largeharvested percentage, and an interaction between these 2 variables (Fig. 4A). Evolutionary change was reduced for lower harvest rates at all large-harvested percentages. Evolutionary change was also reduced for lower large-harvested percentages, but only at high harvest rates. For intermediate harvest rates, evolutionary change was greatest at intermediate largeharvested percentages. This pattern can be attributed to a balance between low removal rates for very low large-harvested percentages and a weakened selective strength at very high large-harvested percentages, due to the harvesting effort being spread across a greater number of individuals in the population.

Our IBM predicted evolutionary change in the Conover \& Munch (2002) experiment to be higher than $25 \%$ only under a combination of extremely high harvest rates and large-harvested percentages (Fig. 4A). However, in reducing the harvest rates from 1 to 0.8 , for example, the evolutionary change drops from $25 \%$ to below $10 \%$ for any large-harvested percentage. A review of several fishery databases suggests that maximum harvest rates in most fisheries do not exceed 0.8 and are generally around 0.6 (Fig. 4B). Several salmon fisheries did have maximum harvest rates similar to the Conover \& Munch (2002) harvest rate (Appendix 1); however, harvest rates in salmon species are generally not consistently high (Labelle et al. 1997, Quinn et al. 2007).
Thus, the magnitude of evolutionary change in the Conover \& Munch (2002) experiment is 2.5 to 5 times the magnitude that would be expected had they used harvest rates more commonly estimated in wild fisheries, such as 0.7 for plaice Pleuronectes platessa or 0.45 for gemfish Rexea solandri (Appendix 1) over the same timescales.

The number of generations required to achieve the magnitude of evolutionary change observed in Conover \& Munch (2002) under different fishery scenarios is illustrated in Fig. 5. With fishing pressures similar to those found in wild fisheries (see above), 15 to 50 or more generations are required to observe the $25 \%$ change in size observed by Conover \& Munch (2002).

\section{DISCUSSION}

The fishing pressure used in Conover \& Munch (2002), which removes $90 \%$ of the largest fish, is unrealistically high and consequently produces unrealistically rapid evolutionary change, approximately a $25 \%$ change in size at age over 4 generations. Individualbased model simulations with more realistic harvest rates in the range of 0.5 to 0.8 suggest that evolutionary change over 4 generations would be less than $10 \%$. Based on these results, either Atlantic silverside are a unique species, and hence, generalizations are not appropriate, or selection pressures are too strong to extend to wild fisheries. Either way, it is important to consider timescales relevant to wild fisheries. A review of empirical studies of fishery-driven evolution sug- 


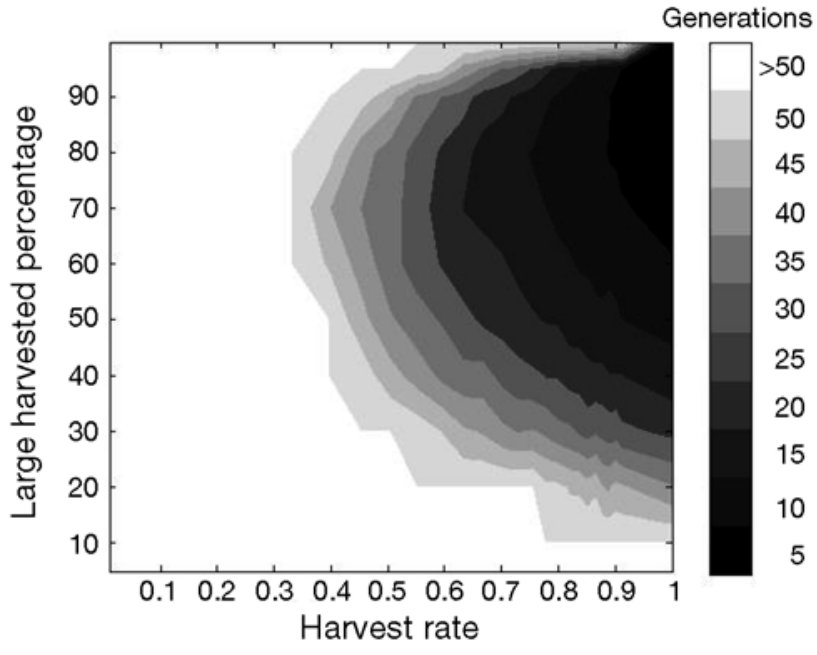

Fig. 5. Contour plot of the number of generations required in the individual-based model (IBM) to reach the same magnitude of evolutionary change in size $(25 \%)$ for different fishery scenarios as Conover \& Munch (2002). Black areas indicate regions where the time scale of change is similar to Conover \& Munch (2002), the lightest areas indicate regions where a time-scale of 50 generations or longer is required

gests that, in wild fisheries, a $25 \%$ evolutionary change in trait values over 30 generations is possible (Jørgensen et al. 2007). Simulations of the Conover \& Munch (2002) experiment over longer timescales with more realistic fishery scenarios suggest that the magnitude of change they observed is comparable to the magnitudes of evolutionary change occurring at slower rates over longer timescales in wild fisheries. Furthermore, the Conover \& Munch (2002) heritability estimate of 0.2 is within the range of 0.2 to 0.3 predicted for wild fish stocks. These results suggest that the magnitude of evolutionary change in the Conover \& Munch (2002) experiment is comparable to that in wild fisheries.

In reality, environmental variability and co-evolution of genetically correlated traits confound evolutionary trends in wild fisheries. Thus, the Conover \& Munch (2002) experimental design also makes 3 further simplifications: (1) maturity is artificially fixed at a constant age; (2) fishing is limited to a single day, just prior to spawning; and (3) individual growth and spawning are density independent (Conover et al. 2005). The Conover \& Munch (2002) experiment has already received criticism for these simplifications, because these patterns of fishing and life-histories are rare in wild fisheries (Hilborn 2006, 2007). In semelparous species, such as Atlantic salmon Salmo salar, age at maturity can vary across a season and selective exploitation of late-running fish may result in a shift towards earlier-running genotypes (Consuegra et al. 2005). Thus, evolution of size at age also depends upon life history trade-offs with age at maturity (Roff 1992). In iteroparous species, predicting the evolutionary response to selective fishing is more complicated: growth, age-at-maturity and size at maturity are all expected to evolve under selective fishing (Kuparinen \& Merila 2007). Furthermore, the evolutionary response of these traits to the spatial and temporal patterns in fishing pressure can affect the direction of evolution. Evolution of earlier or later age-at-maturity depends upon whether sexually mature or immature fish are targeted by the fishery (Law \& Grey 1989). Furthermore, fishery-induced changes in stock density of wild fish populations affect growth and maturity traits (Lorenzen \& Enberg 2002), and changes in stock fecundity affect recruitment in subsequent generations (Jennings et al. 2001). For instance, a study of lake pike Esox lucius has suggested that the evolutionary response of growth and reproductive traits to fishing depended upon a balance between fishing selective pressure and natural selection driven by densitydependent processes (Edeline et al. 2007).

Despite the limitations, the simplified fishery pressure and life-history pattern that Conover \& Munch (2002) applied is also the main strength of their experiment. Unconfounded life-history evolution enabled them to study fishery-driven evolution of traits that are genetically correlated with size at age. Further studies using the Conover \& Munch (2002) model system have found that early life-history traits, such as larval size and larval survival, can evolve when size at age is acted on by fishery pressure (Munch et al. 2005, Walsh et al. 2006). Munch et al. (2005) were also able to use the experimental results to predict that the evolution of genetically correlated early-life history traits was unlikely to affect recruitment in wild fisheries, and hence fishery yields and sustainability. These results indicate that further empirical and modelling studies should focus on how fishery-driven evolution of size at age may impact fecundity of spawning fish, rather than the impact of fishery-driven evolution on offspring quality (Munch et al. 2005).

The model system of Conover \& Munch (2002) has provided important insights into how severe fisherydriven evolution may impact upon yields and sustainability; however, alone it does not provide evidence that fishery-driven evolution is a common problem for wild fisheries. The simulations used in this study demonstrate that the magnitude of evolutionary change observed in Conover \& Munch (2002) is similar to that in wild fisheries, with change occurring more slowly in wild fisheries due to weaker fishery selection pressures. Future model systems that build on the Conover \& Munch (2002) empirical model and their subsequent research (Munch et al. 2005, Walsh et al. 2006) should take realistic features of fisheries into 
account, such as the life history trade-offs between size, maturation and growth, the timing of fishing events and density dependence. Model systems that can explicitly consider the impact of life-history evolution on fishery sustainability and yields will provide fishery managers with the information required to assess the costs of fishery-driven evolution and implement management strategies to ensure evolutionary sustainability of fisheries.

Acknowledgements. We thank the staff and post-graduate students in the School of Zoology at the University of Tasmania for supporting this project. S. Tassell, P. Visconti and 3 anonymous reviewers provided helpful comments on an earlier version.

\section{LITERATURE CITED}

Andersen K, Farnsworth K, Thygesen U, Beyer J (2007) The evolutionary pressure from fishing on size at maturation of Baltic cod. Ecol Model 204:246-252

Blueweiss L, Fox H, Kudzma V, Nakashima D, Peters R, Sams S (1978) Relationships between body size and some life history parameters. Oecologia 37:257-272

Conover DO (2000) Darwinian fishery science. Mar Ecol Prog Ser 208:303-307

> Conover DO, Munch SB (2002) Sustaining fisheries yields over evolutionary time scales. Science 297:94-96

Conover D, Munch S (2007) Faith, evolution, and the burden of proof. Fisheries 32:90-91

Conover D, Arnott S, Walsh M, Munch S (2005) Darwinian fishery science: lessons from the Atlantic silverside (Menidia menidia). Can J Fish Aquat Sci 62:730-737

Consuegra S, De Leaniz CG, Serdio A, Verspoor E (2005) Selective exploitation of early running fish may induce genetic and phenotypic changes in Atlantic salmon. J Fish Biol 67:129-145

de Roos AM, Boukal DS, Persson L (2006) Evolutionary regime shifts in age and size at maturation of exploited fish stocks. Proc R Soc Lond B Biol Sci 273:1873-1880

Dieckmann U, Heino M (2007) Probabilistic maturation reaction norms: their history, strenghts, and limitations. Mar Ecol Prog Ser 335:253-269

Edeline E, Carlson SM, Stige LC, Winfield IJ and others (2007) Trait changes in a harvested population are driven by a dynamic tug-of-war between natural and harvest selection. Proc Natl Acad Sci USA 104:15799-15804

Falconer D, Mackay F (1996) Introduction to quantitative genetics, Vol xv. Harlow, New York

Hallander J, Waldmann P (2007) The effect of non-additive genetic interactions on selection in multi-locus genetic models. Heredity 98:349-359

Heino M, Dieckmann U, Godo O (2002) Measuring probabilistic reaction norms for age and size at maturation. Evolution 56:669-678

Hilborn R (2006) Faith-based fisheries. Fisheries 31:554-555
Hilborn R (2007) Faith, evolution, and the burden of proofreply. Fisheries 32:91-92

Jennings S, Kaiser M, Reynolds J (2001) Marine fisheries ecology, Vol 1. Blackwell Scientific, Oxford

Jørgensen C, Enberg K, Dunlop ES, Arlinghaus R and others (2007) Ecology: managing evolving fish stocks. Science 318:1247-1248

Kuparinen A, Merila J (2007) Detecting and managing fisheries-induced evolution. Trends Ecol Evol 22:652-659

Labelle M, Walters C, Riddell B (1997) Ocean survival and exploitation of coho salmon (Oncorhynchus kisutch) stocks from east coast of Vancouver Island, British Columbia. Can J Fish Aquat Sci 54:1433-1449

> Law R (2000) Fishing, selection and phenotypic evolution. ICES J Mar Sci 57:659-668

> Law R, Grey D (1989) Evolution of yields from populations with age-specific cropping. Evol Ecol 3:343-359

> Lorenzen K, Enberg K (2002) Density-dependent growth as a key mechanism in the regulation of fish populations: evidence from among-population comparisons. Proc R Soc Lond B Biol Sci 269:49-54

Munch S, Walsh M, Conover DO (2005) Harvest selection, genetic correlations, and evolutionary changes in recruitment: one less thing to worry about? Can J Fish Aquat Sci 62:802-810

Olsen EM, Heino M, Lilly GR, Morgan MJ, Brattey J, Ernande B, Dieckmann U (2004) Maturation trends indicative of rapid evolution preceded the collapse of northern cod. Nature 428:932-935

Quinn TP, Hodgson S, Flynn L, Hilborn R, Rogers DE (2007) Directional selection by fisheries and the timing of sockeye salmon (Oncorhynchus nerka) migrations. Ecol Appl 17:731-739

Reznick DN, Ghalambor CK (2005) Can commercial fishing cause evolution? Answers from guppies (Poecilia reticulata). Can J Fish Aquat Sci 62:791-801

Rijnsdorp A (1993) Fisheries as a large-scale experiment on life-history evolution: disentangling phenotypic and genetic effects in maturation and reproduction of North Sea plaice, Pleuronectes platessa L. Oecologia 96: 391-401

Roff D (1992) The evolution of life histories: theory and analysis. Chapman and Hall, New York

Sinclair A, Swain D, Hanson J (2002) Measuring changes in the direction and magnitude of size-selective mortality in a commercial fish population. Can J Fish Aquat Sci 59: 361-371

Stokes K, Law R (2000) Fishing as an evolutionary force. Mar Ecol Prog Ser 208:307-313

Swain D, Sinclair A, Hanson J (2007) Evolutionary responses to size-selective mortality in an exploited fish population. Proc R Soc Lond B Biol Sci 274:1015-1022

Walsh MR, Munch SB, Chiba S, Conover DO (2006) Maladaptive changes in multiple traits caused by fishing: impediments to population recovery. Ecol Lett 9:142-148

Williams E, Shertzer K (2005) Effects of fishing on growth traits: a simulation analysis. Fish Bull 103:392-403

Wright PJ (2007) Understanding the maturation process for field investigations of fisheries-induced evolution. Mar Ecol Prog Ser 335:279-283 
Appendix 1. Data sources for the review of maximum harvest rates (proportion of the population removed by fishing each year) in wild fisheries. Included are 82 stocks of 51 different species

\begin{tabular}{|c|c|c|c|c|c|}
\hline Common name & Scientific name & Region & Location & est rate $\left(\mathrm{yr}^{-1}\right)$ & Source \\
\hline Albacore & Thunnus alalunga & Central Pacific & General estimate & 0.15 & Cox et al. (2002) \\
\hline Bigeye tuna & Thunnus obesus & Central Pacific & General estimate & 0.14 & Cox et al. (2002) \\
\hline Billfish & $\begin{array}{l}\text { Makaira sp. } \\
\text { Tetrapturus sp. } \\
\text { Istiophorus platypterus }\end{array}$ & Central Pacific & General estimate & 0.21 & Cox et al. (2002) \\
\hline Blue marlin & Makaira sp. & Central Pacific & General estimate & 0.27 & Cox et al. (2002) \\
\hline Blue shark & Prionace glauca & Central Pacific & General estimate & 0.18 & Cox et al. (2002) \\
\hline Blue whiting & Micromesistius poutassou & NE Atlantic & ICES Sub-areas I-IX, XII \& XIV & 0.66 & ICES CIEM (2007) \\
\hline Bluefish & Pomatomus saltatrix & USA & East Coast & 0.40 & $\begin{array}{l}\text { Ransom Myers' Stock } \\
\text { Recruitment Database }\end{array}$ \\
\hline Bocaccio & Sebastes paucispinis & USA & West coast & 0.24 & $\begin{array}{l}\text { Ransom Myers' Stock } \\
\text { Recruitment Database }\end{array}$ \\
\hline Brazilian sardine & Sardinella brasiliensis & Brazil & South-east & 0.77 & $\begin{array}{l}\text { Ransom Myers' Stock } \\
\text { Recruitment Database }\end{array}$ \\
\hline Brown shark & Carcharhinus longimanus & Central Pacific & General estimate & 0.08 & Cox et al. (2002) \\
\hline Chum salmon & Oncorhynchus keta & Canada & Johnstone Strait & 0.67 & $\begin{array}{l}\text { Ransom Myers' Stock } \\
\text { Recruitment Database }\end{array}$ \\
\hline Cod & Gadus morhua & NE Atlantic & $\begin{array}{l}\text { ICES Divisions VIIe-k } \\
\text { ICES Sub-divisions } 22 \text { to } 24 \\
\text { ICES Sub-divisions } 25 \text { to } 32 \\
\text { Faroe Plateau } \\
\text { ICES Division Va } \\
\text { Norwegian Coast }\end{array}$ & $\begin{array}{l}0.67 \\
0.86 \\
0.75 \\
0.56 \\
0.59 \\
0.46\end{array}$ & $\begin{array}{l}\text { ICES CIEM (2007) } \\
\text { ICES CIEM 2007 } \\
\text { ICES CIEM (2007) } \\
\text { ICES CIEM (2007) } \\
\text { ICES CIEM (2007) } \\
\text { ICES CIEM (2007) }\end{array}$ \\
\hline Coho salmon & Oncorhynchus kisutch & Canada & Strait of Georgia & 0.96 & Labelle et al. (1997) \\
\hline False scad & Decapterus rhonchus & NW Africa & - & 0.58 & $\begin{array}{l}\text { Ransom Myers' Stock } \\
\text { Recruitment Database }\end{array}$ \\
\hline Gemfish & Rexea solandri & Australia & West Australia & 0.45 & Smith \& Wayte (2004) \\
\hline Haddock & Melanogrammus aeglefinus & NE Atlantic & $\begin{array}{l}\text { Faroe Islands } \\
\text { West of Scotland } \\
\text { Rockall } \\
\text { ICES Divisions VIIb-k } \\
\text { North Sea } \\
\text { Icelandic } \\
\text { NE Arctic }\end{array}$ & $\begin{array}{l}0.51 \\
0.60 \\
0.61 \\
0.53 \\
0.68 \\
0.54 \\
0.60\end{array}$ & $\begin{array}{l}\text { ICES CIEM (2007) } \\
\text { ICES CIEM (2007) } \\
\text { ICES CIEM (2007) } \\
\text { ICES CIEM (2007) } \\
\text { ICES CIEM (2007) } \\
\text { ICES CIEM (2007) } \\
\text { ICES CIEM (2007) }\end{array}$ \\
\hline Hake & Merluccius merluccius & Atlantic Ocean & South-west & 0.44 & $\begin{array}{l}\text { Ransom Myers' Stock } \\
\text { Recruitment Database }\end{array}$ \\
\hline Hake & Urophycis earllii & NE Atlantic & $\begin{array}{l}\text { ICES Divisions IIIa, IV, VI, VII, VIIIa, b } \\
\text { ICES Divisions IIIa, IV, VI, VII, VIIIa,b } \\
\text { ICES Divisions Divisions VIIIc and Ixa }\end{array}$ & $\begin{array}{l}0.35 \\
0.54 \\
0.40\end{array}$ & $\begin{array}{l}\text { ICES CIEM (2007) } \\
\text { ICES CIEM (2007) } \\
\text { ICES CIEM (2007) }\end{array}$ \\
\hline Halibut & Hippoglossus hippoglossus & NE Atlantic & Greenland & 0.48 & ICES CIEM (2007) \\
\hline Herring & Clupea harengus & NE Atlantic & $\begin{array}{l}\text { ICES Division Via } \\
\text { ICES Divisions VIId \& IIIa } \\
\text { Bothnian Sea } \\
\text { ICES Sub-divisions } 22-24 \text { and } \\
\text { Division IIIa } \\
\text { ICES Sub-divisions } 25 \text { to } 29 \text { and } 32 \\
\text { Gulf of Riga } \\
\text { Archipelago and Bothnian Seas } \\
\text { Icelandic } \\
\text { Norway }\end{array}$ & $\begin{array}{l}0.65 \\
0.77 \\
0.21 \\
0.54 \\
0.37 \\
0.51 \\
0.20 \\
0.34 \\
0.42\end{array}$ & $\begin{array}{l}\text { ICES CIEM (2007) } \\
\text { ICES CIEM (2007) } \\
\text { ICES CIEM (2007) } \\
\text { ICES CIEM (2007) } \\
\text { ICES CIEM (2007) } \\
\text { ICES CIEM (2007) } \\
\text { ICES CIEM (2007) } \\
\text { ICES CIEM (2007) } \\
\text { ICES CIEM (2007) }\end{array}$ \\
\hline Horse mackerel & Trachurus trachurus & NW Africa & - & 0.72 & $\begin{array}{l}\text { Ransom Myers' Stock } \\
\text { Recruitment Database }\end{array}$ \\
\hline Horse mackerel & Trachurus mediterraneus & Black Sea & - & 0.73 & $\begin{array}{l}\text { Ransom Myers' Stock } \\
\text { Recruitment Database }\end{array}$ \\
\hline King mackerel & Scomberomorus cavalla & USA & Gulf of Mexico & 0.53 & $\begin{array}{l}\text { Ransom Myers' Stock }{ }^{a} \\
\text { Recruitment Database }\end{array}$ \\
\hline Mackerel & Scomber scombrus & Black Sea & North Sea & 0.75 & $\begin{array}{l}\text { Ransom Myers' Stock }{ }^{\mathrm{a}} \\
\text { Recruitment Database }\end{array}$ \\
\hline Mahimahi & Coryphaena hippurus & $\begin{array}{l}\text { NE Atlantic } \\
\text { Central Pacific }\end{array}$ & $\begin{array}{l}\text { North Sea } \\
\text { General estimate }\end{array}$ & $\begin{array}{l}0.32 \\
0.05\end{array}$ & Cox et al. $(2007)$ \\
\hline Megrim & Lepidorhombus whiffiagonis & NE Atlantic & ICES Divisions VIIIC and IXa & 0.55 & ICES CIEM (2007) \\
\hline
\end{tabular}


Appendix 1 (continued)

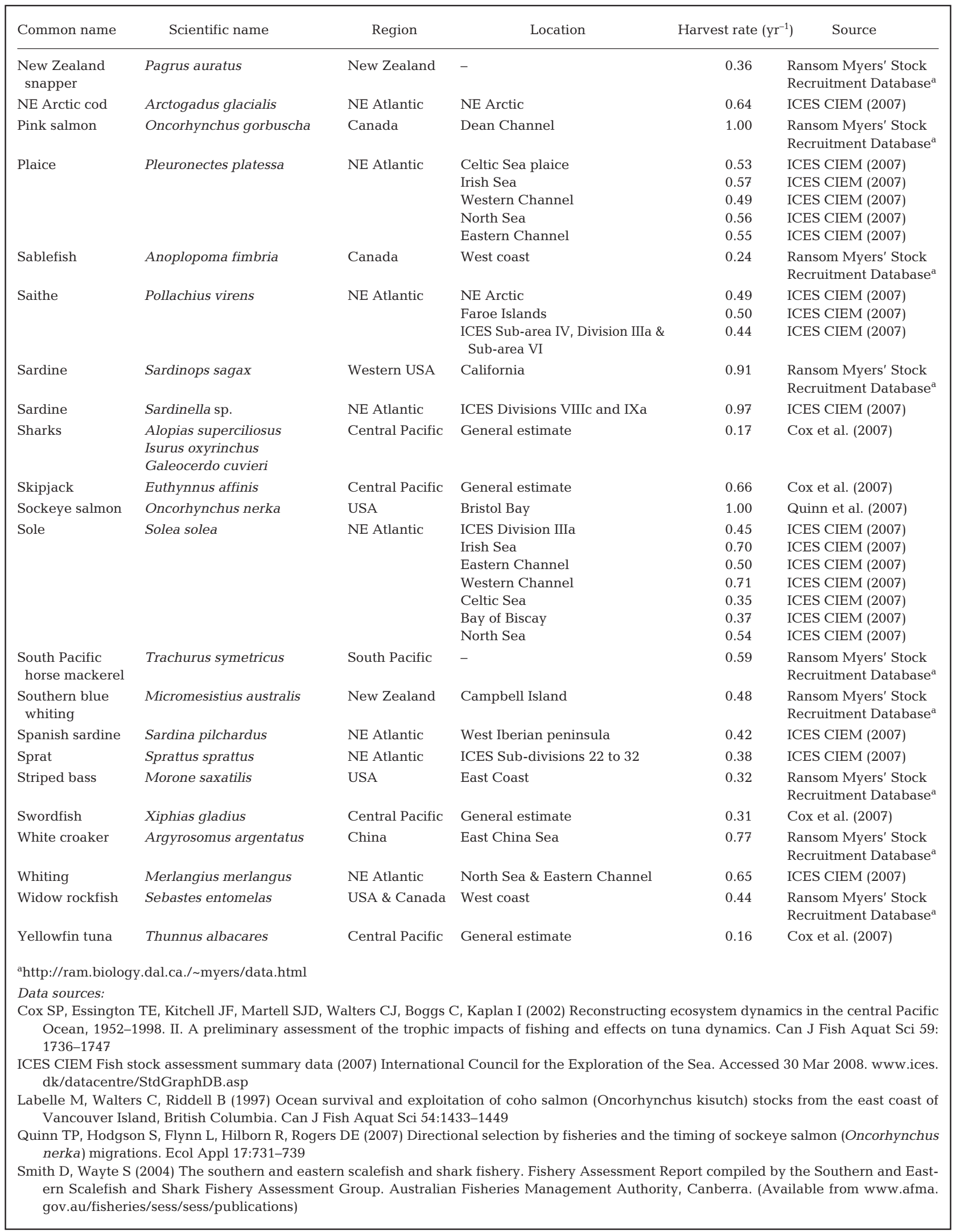

